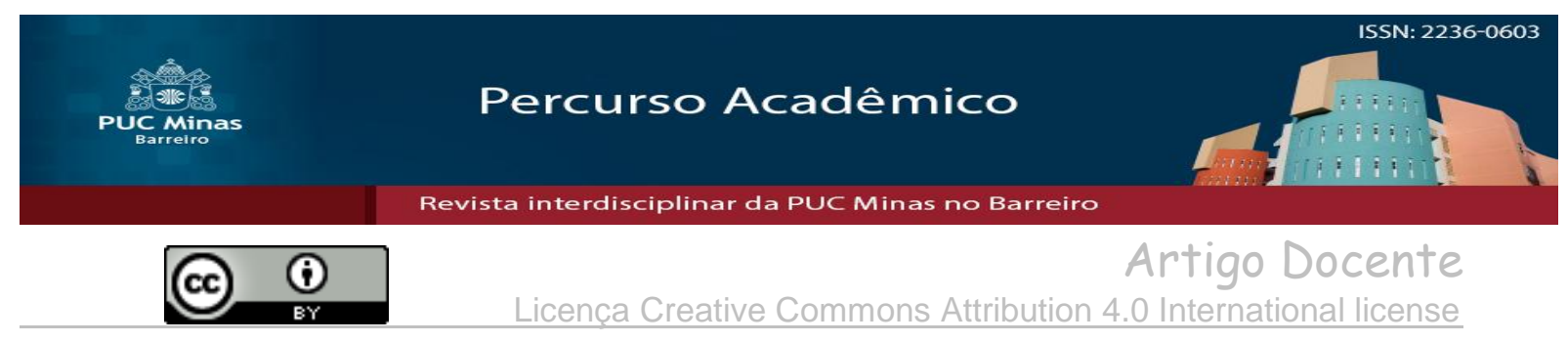

\title{
Creche penitenciária: a inclusão que exclui
}

\author{
Prison Nursery: the inclusion that excludes
}

\author{
Klelia Canabrava Aleixo ${ }^{1}$ \\ Flávia Ávila Penido
}

\begin{abstract}
Resumo
O presente artigo visa discutir o art. 89 da Lei de Execução Penal, que prevê a criação de creche em penitenciárias para abrigar crianças cuja responsável estiver presa. Para tal, será utilizado o procedimento metodológico dedutivo a partir de pesquisas bibliográfica e documental. Este dispositivo legal foi considerado como um avanço, no sentido de incluir direitos voltados a assegurar o exercício da maternidade pelas mães presas e a assistência aos seus filhos. Paradoxalmente, a norma permite que crianças vivam no ambiente prisional, excluindo-a do ambiente social, e sujeita a mãe ao exercício da maternidade condicionado às regras do sistema prisional. À luz do Direito, a privação da liberdade da mulher mãe, não poderia afetar o seu direito de exercer a maternidade e conviver com seu filho, nem o direito do filho de conviver com ela. Acredita-se que são necessárias outras medidas - sugeridas neste texto - que viabilizem o exercício dos direitos, minimizando os impactos da prisão sobre ambos.
\end{abstract}

Palavras-chave: Creche. Penitenciária. Inclusão. Exclusão.

\begin{abstract}
This article aims to debate the article 89 of the Brazilian Law of Criminal Enforcement, which prescribes the creation of nurseries in penitentiaries for the children of incarcerated mothers. In order to do this debate, we adopted a deductive approach based on literature and documentary review. This law was considered an advancement in the sense that it included the rights of imprisoned mothers to maternity and to parenting. Paradoxically, the law permits that the children live in the prison environment, excluding them from the social environment, and also subjects the mothers to rear their children according to the prison laws. The light of the right, the privation of liberty of woman mother, could not affect your right to exercise the mother hood and to live with your child, nor the right of the child to live with her. In this text, it is pointed out that other measures are necessary in order to make possible for them to exercise their rights and to minimize the impact of the detention on both mothers and children.
\end{abstract}

Keywords: Nursery. Penitentiary. Inclusion. Exclusion.

\footnotetext{
Artigo recebido em 27 de Setembro de 2017 e aprovado em 23 de Maio de 2018.

${ }^{1}$ Doutora em Políticas Públicas e Formação Humana pela Universidade do Estado do Rio de Janeiro (2011). Mestre em Direito, área de concentração em Ciências Penais, pela Universidade Federal de Minas Gerais (2003). Especialista em Docência no Ensino Superior pela Pontifícia Universidade Católica de Minas Gerais (2005). Bacharel em Filosofia pela Universidade Federal de Minas Gerais (1998). Bacharel em Direito pela Pontifícia Universidade Católica de Minas Gerais (1998). Advogada. Professora Adjunta de Direito Penal, Criminologia e Política Criminal nos cursos de graduação e pós-graduação (Mestrado e Doutorado) da Pontifícia Universidade Católica de Minas Gerais. E-mail: kleliaaleixo@gmail.com

${ }^{2}$ Doutoranda e mestra em Direito Processual pela Pontifícia Universidade Católica de Minas Gerais. Especialista em Direito Público. Bacharel em Direito pela Pontifícia Universidade Católica de Minas Gerais. Pesquisadora e vicediretora financeira do Instituto Popperiano de Estudos Jurídicos (INPEJ). Pesquisadora no Centro de Pesquisa e Extensão em Execução Penal (CEPEX). Membro da diretoria executiva da Associação de Proteção e Assistência aos Condenados (APAC) de Santa Luzia / MG. Advogada criminalista. E-mail: f.avilapenido@gmail.com
} 


\section{Introdução}

O presente artigo visa discutir o art. 89 da Lei de Execução Penal (BRASIL, 1984), cuja redação dispõe que a penitenciária de mulheres será dotada de creche para abrigar crianças maiores de seis meses e menores de sete anos, com a finalidade de assistir à criança desamparada cuja responsável estiver presa. Para estabelecer tal discussão, utilizar-se-á o procedimento metodológico dedutivo com a realização de pesquisas bibliográfica e documental.

O referido dispositivo legal - que teve a redação alterada pela Lei 11.942/09 (BRASIL, 2009) - foi considerado como um avanço no sentido de incluir direitos voltados a atender às necessidades específicas das mães presas e assegurar a assistência a seus filhos. No entanto - paradoxalmente - observa-se que ele acaba permitindo que crianças vivessem no ambiente prisional por toda a primeira infância, excluindo-as do meio social.

A partir de uma análise jurídica, verifica-se que o encarceramento de crianças, em razão da condenação de sua genitora, consiste na extensão da sanção àquele que acabou de nascer, inobstante o princípio da pessoalidade da pena, previsto no art. $5^{\circ}$, XLV, da Constituição da República Federativa do Brasil de 1988 (CRFB/1988). (BRASIL, 1988).

A Lei do Ventre Livre, assinada pela Princesa Isabel e promulgada em 28 de setembro de 1871, assegurou - formalmente - a liberdade de todos os filhos de mulheres escravas nascidos a partir da lei, libertando-os da condição de escravos. Em um retrocesso histórico, a legislação brasileira acabou por restringir a liberdade das crianças nascidas do ventre de mães presas que, não por acaso, são em sua maioria negras (BRASIL, 1871).

Na mais cruel sucessão, permite-se a violação dos direitos da criança infligindo a ela as penas impostas à sua mãe, condicionando seu desenvolvimento primário aos efeitos da prisionalização. Isso porque a criança crescerá circunscrita ao ambiente carcerário com todas as privações inerentes a esse, além de estar sujeita à violência institucional que fere a autodeterminação do sujeito a partir da imposição de regras disciplinares, limites e toda sorte de violências.

A mãe, sujeita ao adestramento imposto neste ambiente, não poderá exercer com liberdade o direito de cuidar e educar seu filho, que também será submetido ao poder disciplinar institucionalizado exercido na prisão. Por tais razões, acredita-se que são 
necessárias outras medidas, explicitadas neste texto, que viabilizem o exercício da maternidade pela mulher mãe condenada à pena privativa de liberdade e o direito à assistência a criança filho, minimizando os impactos da prisão sobre ambos.

\section{A transcendência da pena privativa de liberdade que alcança os filhos de mães presas}

Uma das maiores demonstrações de que a pena privativa de liberdade consiste na imposição de um poder ilegítimo do Estado está na transcendência dos seus efeitos, que recaem sobre os familiares das pessoas presas.

A Convenção Americana sobre Direitos Humanos (artigo 5.1.3) e a CRFB/1988 (art. $5^{\circ}$, inciso XLV) prescrevem que nenhuma pena ultrapasse a pessoa do condenado. Inobstante as previsões legais, a estigmatização sofrida pela família da pessoa presa, o vexame da revista imposta para a visita e a prática das relações sexuais subordinadas à maior ou menor liberalidade da administração penitenciária, são apenas algumas demonstrações da transcendência do poder de punir (ZAFFARONI, 2003).

No estudo histórico intitulado Dante Criminalista, Carrara (1870) revelou que não havia visto ramo da ciência ou da arte no qual Alighieri não antevisse o pensamento e não profetizasse muitas verdades, também no campo do Direito Penal. Sobre a questão da penalidade, registrou que ao narrar a punição imposta ao Conde Ugolino - traidor de Pisa - Dante corajosamente protestou contra a injustiça de mesclar na culpa do pai os filhos inocentes e desaprovou a condenação deles (CARRARA, 1870).

Em tempos de encarceramento de mulheres, verifica-se que a materna culpa alcança seus filhos inocentes. Conforme verificado no INFOPEN mulheres, entre os anos de 2000 e 2014, houve um aumento expressivo do encarceramento de mulheres. No período, o aumento foi de 567,4\%, enquanto a média de crescimento do encarceramento masculino foi de 220,20\%. Quant

o ao seu perfil, em geral, as mulheres presas são jovens, têm filhos, são responsáveis pelo sustento familiar, possuem baixa escolaridade, advêm de extratos sociais economicamente desfavorecidos e foram presas por crimes relacionados ao comércio ilegal de drogas. Quanto à sua raça, 67\% das mulheres presas são negras, representando duas em cada três presas (BRASIL, 2014).

Tendo em vista que, em geral, as mulheres presas têm filhos, as questões referentes ao exercício da maternidade e da convivência familiar no ambiente prisional são relevantes e complexas. 
À luz do Direito, a privação da liberdade da mulher mãe, seja provisória ou definitiva, não poderia afetar nem o seu direito de exercer a maternidade e conviver com seu filho, nem o direito do filho de conviver com ela. No entanto, enquanto manifestação de poder abusivo, tal medida afeta e limita ambos.

Nesse contexto, observa-se que, sob o pretexto de atender às necessidades, específicas das mulheres, mães presas, e assegurar o direito à assistência a seus filhos, a Lei 11.942/09 alterou a redação dos artigos 14, $§ 3^{\circ} ; 83$ e 89 da Lei de Execução Penal (LEP). O art. 89 da LEP dispõe que a penitenciária de mulheres será dotada de creche para abrigar crianças maiores de seis meses e menores de sete anos, com a finalidade de assistir a criança desamparada cuja responsável estiver presa. Tais dispositivos legais foram reconhecidos como considerável avanço no sentido de atender às necessidades específicas das mulheres mães presas e assegurar a assistência a seus filhos (BRAGA, 2015b).

$\mathrm{Na}$ verdade, trata-se de norma que registra em lei que a pena ultrapassa, sim, a pessoa da mãe presa alcançando seus filhos que também são encarcerados. Nesse contexto, observa-se que a suposta garantia de direitos gera a sua própria violação, fazendo com que, num retrocesso histórico, quase cento e cinquenta anos após a Lei do Ventre Livre, a legislação brasileira parece ter restringido, de maneira semelhante, a liberdade daqueles que nascem do ventre de mães presas que, não por acaso, são em sua maioria negras.

Em última instância, tal suposta melhoria para garantia de direitos acaba por reforçar o encarceramento, já que "[...] à medida que se melhoram as prisões, paradoxalmente prendem-se mais mulheres e crianças, sob o discurso benevolente e paternalista de que a vida atrás das grades é o melhor destino para ambas" (BRAGA, 2015b, p. 532).

Portanto, conforme alertado por Beiras, (2017), a melhor opção nunca pode passar por "melhorar" uma instituição tão selvagem e violenta como o cárcere, senão em pensar, primeiro, cada vez mais na sua redução.

Sobre a questão, sobram perplexidades, obviedades e indagações. Dentre as muitas: como uma criança pode viver na prisão? Como uma criança pode viver em uma prisão brasileira, internacionalmente reconhecida por sua violência institucional? A creche penitenciária é dispositivo voltado para assegurar a transcendência da pena com vistas a alcançar e controlar os filhos de mães consideradas perigosas? Busca-se com tais creches prevenir, ainda na infância, os possíveis desvios daqueles que constituirão, 
num futuro próximo, as classes perigosas?

\section{Da afetação dos direitos das mulheres mães e das crianças filhas: impossibilidade da garantia de direitos na prisão}

No tocante ao direito da criança, verifica-se que a nova redação do art. 89 da LEP fundamenta-se na ideologia tutelar que norteou as legislações menoristas anteriores ao Estatuto da Criança e do Adolescente e que continua fortemente presente no Brasil: "Dessa forma, quando eram atendidos pela rede de assistência social estatal os menores eram considerados objeto de tutela e de medidas aparentemente protetivas, mas, na realidade elas eram voltadas para o seu ajustamento e disciplinarização" (SCHEINVAR, 2009, p. 82-83).

No entanto, à luz do Estatuto da Criança e do Adolescente (ECA), crianças e adolescentes são titulares de direitos que devem ser assegurados pela família, pela sociedade e pelo Estado com prioridade absoluta (BRASIL, 1990). Tal prioridade implica o reconhecimento de que a observância dos direitos da criança está em primeiro lugar, devendo ocupar espaço primordial na escala de realização do mundo jurídico, antecedendo quaisquer outros interesses dos adultos. Por tal razão, os direitos à liberdade e à convivência familiar da criança não podem estar subordinados a razões de segurança pública ínsitas na prisão de sua mãe.

Sob qualquer justificativa é inconcebível sequer cogitar que uma criança possa viver na prisão, menos ainda em uma prisão no Brasil, cuja característica genocida coloca em risco a sua própria vida. É evidente o desrespeito à criança enquanto pessoa em condição peculiar de desenvolvimento. Nas palavras de Braga (2015b, p. 536): “[...] viver na prisão limita o mundo. Uma criança na prisão tem não só seus estímulos drasticamente limitados, como também sua vida atravessada pelo dispositivo carcerário. O mundo que lhe recebe é um mundo de regras, violências, limites, trancas".

A prisão é também incompatível com o exercício pleno da maternidade, pois, nela tal exercício se inscreve no regime de disciplina, normas e sanções que acabam conformando um certo modo admitido de ser mãe:

\footnotetext{
Além de ferir a autonomia da mulher presa, desrespeitando os desejos, crenças e valores que conformariam seu modo próprio de ser mãe, as normas e sanções do cárcere instituem um regime de medo constante, já que qualquer passo dado fora do estabelecido pode levar à separação da criança e a “expulsão" do espaço materno-infantil (BRAGA, 2015b, p. 538).
} 
Observa-se que a maternidade pode ser considerada peça-chave no discurso da ressocialização. Ela é considerada o caminho que leva a mulher criminosa de volta ao seu destino, da sua "verdadeira natureza feminina" de ser mãe. Nesse contexto, a mulher presa encontra-se mais intensamente encarcerada também no papel dela esperado de seu devir mãe (BRAGA, 2015b, 530). O exercício da maternidade na prisão é o caminho que viabiliza o retorno da mulher criminosa demonizada à condição sacralizada de mãe. Portanto, a defesa da melhoria da situação das mulheres e crianças que vivem nas prisões brasileiras passa, preliminarmente, pelo reconhecimento da prisão como espaço de violação de direitos, portanto, incapaz de assegurá-los no seu interior.

Conforme identificado por Ferrajoli (2016), o cárcere - sobre múltiplos aspectos - equivale a uma contradição institucional, uma patologia não reformável do Estado de Direito:

\begin{abstract}
É um lugar confiado ao controle total do estado, mas em cujo interior não regem controles nem regras senão - sobretudo - a lei do mais forte: a lei da força pública dos agentes penitenciários e a força privada dos presos mais prepotentes e organizados. É uma instituição pública dirigida à custódia dos cidadãos mas que não logra garantir os direitos fundamentais mais elementares, começando pelo direito à vida. Gera uma vida completamente artificial, produzida pelo direito, mas que - em seu interior, de fato reproduz o Estado de natureza, sem regras e sem direito, onde sobrevive o homo homini lúpus onde a máxima segurança externa acompanha a máxima insegurança interna (FERRAJOLI, 2016, p. 7, tradução nossa).
\end{abstract}

Ontologicamente, por sua natureza mesma de prática de segregação, a pena privativa de liberdade viola os direitos fundamentais e a dignidade das pessoas. (FERRAJOLI, 2016). Por tal razão, é impossível assegurar direitos em seu interior.

Beiras (2017), ao esboçar as linhas gerais do que definiu como "garantismo radical" também se mostra convencido da impossibilidade estrutural de que - no cárcere - os direitos fundamentais das pessoas presas sejam respeitados. Portanto, os problemas criados pela prisão como o da violação do direito de liberdade dos filhos das mulheres presas e da restrição ao direito à convivência familiar de ambos, não devem ser resolvidos na prisão, mas fora dela "[...] sino, en todo caso, en el exterior de la misma, en la própria sociedade que crea, que produce, que alimenta e que reproduce a la cárcel" (BEIRAS, 2017, p. 75).

Tendo em vista que a criança filha da mulher presa não foi condenada à pena privativa de liberdade, é imperativo que haja alteração no art. 89 da Lei de Execução Penal. Conforme registrado na pesquisa Dar à luz na sombra realizada pelo Instituto de Pesquisa Econômica Aplicada (IPEA), em parceria com o Ministério da Justiça: 
Tanto presas quanto especialistas e funcionárias acham que o modelo de creche externa à unidade prisional é a melhor solução para o cuidado com as crianças cujas mães estejam em situação de prisão. Todas elas foram unânimes em ressaltar que o cárcere não é lugar ideal para a permanência de crianças, sendo necessário outro espaço para garantir o contato entre mãe e filhas (BRASIL, 2015, p. 76).

Nesse sentido, os próprios órgãos estatais propõem a alteração do art. 89 da Lei de Execução Penal, que prevê creche na penitenciária de mulheres, para que o dispositivo legal seja no sentido de garantir o acesso da criança a creches da rede pública, externas ao ambiente prisional e abertas a toda a comunidade (BRASIL, 2015).

Cabe mencionar, ainda, como possível alternativa voltada para minimizar os impactos da prisão sobre as mulheres presas com filhos sob a sua responsabilidade, o previsto pela Lei 26.472 da Argentina que autoriza o juiz da execução a decidir sobre o cumprimento da pena imposta em prisão domiciliar para mulher grávida ou mãe (BEIRAS, 2017).

A Lei 13.257 de 2016, conhecida como Marco da Primeira Infância, estabeleceu diretrizes para a formulação e a implementação de políticas públicas para a primeira infância, considerando a relevância dos primeiros anos de vida no desenvolvimento infantil. Promoveu ainda uma alteração no Código de Processo Penal, prevendo a possibilidade de substituição da prisão preventiva pela prisão domiciliar nos casos de gestante, ou mulher com filho de até 12 anos de idade incompletos. Tal previsão poderia ser ampliada para abarcar também as pessoas condenadas que se encontrarem na mesma situação (BRASIL, 2016).

Por fim, para além do indulto e da comutação que podem continuar sendo concedidos às mulheres mães presas, tal como o promulgado em 12 de abril de 2017, é urgente descriminalizar o comércio ilegal de drogas no Brasil, cuja criminalização é a principal razão das prisões de mulheres no país e que inaugura a necessidade de outras discussões.

\section{Dos efeitos da prisionalização sobre as crianças e mulheres mães}

A prisionalização diz respeito à interiorização de atitudes, modelos de comportamentos e valores característicos da subcultura carcerária (BARATTA, 2011). Trata-se da assimilação do ambiente prisional e o consequente não reconhecimento do espaço livre pela pessoa presa que se desgarra das diretrizes da vida em liberdade para que, em um processo de aculturação e internalização dos elementos daquela nova realidade, passe a identificar-se com os modelos comportamentais e valores próprios do 
cárcere. Consiste em um processo de conformação da subjetividade da pessoa presa ao padrão imposto.

Verifica-se que a prisão - enquanto instituição - não exclusivamente; sobretudo disciplinar, atua como instituição de controle, promove a repressão que anula, cega e cala, mas - principalmente - exerce uma função configuradora, que molda, afirma e faz falar (FOUCAULT, 2012).

Esta é a perspectiva que não pode ser ignorada quando se pretende realizar qualquer estudo ou intervenção no sistema penitenciário. Nas suas múltiplas funcionalidades, ele é também estruturado para promover a alienação do sujeito encarcerado, moldando-o conforme o poder disciplinar a que está sujeito pela imposição de limites pelo Estado na vida intramuros.

Se os efeitos da prisionalização, como resultado da disciplinarização e normalização dos corpos são perceptíveis nos adultos, eles são muito mais intensos nas crianças submetidas ao cárcere desde o nascimento.

A literatura indica que é na primeira infância (do nascimento até os seis primeiros anos de vida) que serão formadas as estruturas que serão fundamentais para o desenvolvimento do sujeito por toda a vida. Didonet $^{3}$ (2016) explica que - ao nascer - a criança já traz muitos dados da interação com a mãe, o pai, e a família em geral durante a gestação, sendo que esse período da gestação é determinante de muitos aspectos que a criança poderá desenvolver ao longo de sua existência ${ }^{4}$. Já a primeira infância constituise em anos decisivos e fundamentais da existência humana porque é neste período (dos seis primeiros anos) que se formam as estruturas da personalidade humana, a inteligência, a afetividade e o relacionamento social. É quando acontecem as transformações essenciais que vão determinar o que a criança será ao longo da vida, a partir da interação de suas potencialidades com o meio social e ambiental. O desenvolvimento das potencialidades se dá naquilo e na medida em que o meio é estímulo, tornando fundamental que o ser humano esteja inserido em um ambiente social em que ele possa se expressar e receber a influência do meio. Nessa influência

\footnotetext{
${ }^{3}$ A entrevista de Didonet faz parte de uma série de oito vídeos lançados pela TV Câmara sobre o Marco Legal da Primeira Infância (Lei 13.257 2016), com entrevistas de especialistas sobre a primeira infância. ${ }^{4}$ Como exemplo, há o relato de Thamyris, que foi presa com o filho de três meses nos braços. Na ocasião da prisão, apanhou muito, o que também ocorreu com seu filho, que foi golpeado na lateral do olho. Dez meses mais tarde, já numa unidade prisional, o pediatra que cuidava da criança preocupava-se com o estado emocional do menino: ele não sorria sob nenhum estímulo. Há também o relato de Gardênia que afirma que sua filha com então 17 anos, nascida no cárcere, tem dificuldades de expressar os sentimentos, e bate a cabeça na parede todas as noites, até adormecer (QUEIROZ, 2015).
} 
recíproca da potencialidade inata da criança com os estímulos do meio é que vai sendo formada a sua identidade. Como resultado dos estímulos externos, desde a gestação, a criança pode criar marcas que se incrustam e se incorporam na sua subjetividade.

Nesta perspectiva da importância do meio para o desenvolvimento infantil, observa-se o relato de Francisca, presa que só tinha a oferecer à sua filha um banho de sol, através dos furos das grades (QUEIROZ, 2015). A limitação estrutural do ambiente carcerário desde seus muros evidencia a sua inadequação para o nascimento e crescimento de uma criança, vez que a limitação espacial e social vai resultar na limitação do próprio desenvolvimento da criança, sobretudo em relação à afetividade e socialização. Casos como o de Cássia, a filha de Francisca, também demonstram tal limitação, vez que, na prisão a menina era arredia, chorava muito e não gostava de interagir com ninguém, limitando sua existência em poucos metros quadrados. Quando a direção do presídio localizou a família de Francisca, a criança ficou fora do cárcere por uma semana, desfrutando de passeios com a família. No seu retorno, Cássia pedia colo para outras pessoas, aprendeu a bater palmas e sorria espontaneamente (QUEIROZ, 2015). Há também o caso de Luiza - de quatro anos, nascida na prisão que não conhecia as estrelas. Como vivia na cela com sua mãe e seguia o regime disciplinar da unidade prisional, era recolhida na cela todos os dias às 17 horas, de forma que não conhecia o céu no período noturno. Em situação ocasional, quando deixou o presídio a noite, espantou-se com as estrelas no céu (BRAGA, 2015b).

Acresce ao fator estrutural e disciplinar a castração do exercício da maternidade. Os valores passados da mãe à criança na prisão são limitados, conquanto a própria maternidade também o é. Isso porque a maternidade fica condicionada ao cumprimento das regras do sistema prisional, em detrimento de se estabelecer uma rotina que a genitora entende mais benéfica à criança ${ }^{5}$. $\mathrm{O}$ acesso aos postos de trabalho é negado sob a justificativa de que as internas precisam cuidar de suas crianças em tempo integral, reforçando o discurso de que o sistema prisional as ensinaria a serem mães. Isso não leva em conta que o mesmo Estado que se propõe a "ensinar" a maternidade, se omitiu na oferta de educação, amparo e proteção em situações de violência que comumente se verificam na história dessas mulheres, antecedente à prisão. Contrapõe-se também à sua omissão em fornecer itens essenciais para o cuidado da criança como, por exemplo,

\footnotetext{
${ }^{5}$ Conforme relatado por Braga; Angotti (2015), no Centro de Referência à Gestante Privada de Liberdade, em Minas Gerais, gera desabono disciplinar a conduta da mãe de dormir na mesma cama que o filho, em detrimento de utilizar o berço e a oferta de alimentação diferente do que o estabelecimento determina.
} 
roupas. Considerando que $47 \%$ das mulheres presas não recebem visitas, percentual superior à realidade no Centro de Referência à Gestante Privada de Liberdade (CRGPL), onde apenas 6 das 67 mães privadas de liberdade recebem visitas regulares ${ }^{6}$, os itens essenciais para o crescimento do bebê dependeriam de fornecimento pelo próprio Estado coator, mas, ante a omissão desse, tornam-se necessárias doações para suprir as necessidades (MARTINO, 2017).

Esta função propedêutica, supostamente desenvolvida pelo sistema prisional de fabricar mães, não consiste propriamente em oportunizar o exercício da maternidade, mas de normalizá-lo. A imposição de restrição alimentar até os seis meses de vida, quando só então é oferecida a papinha, é um sintoma da castração do direito de exercer a maternidade. É também exemplificativo o relato colhido pelo Instituto Terra, Trabalho e Cidadania (ITTC) quando reproduz a narrativa de uma mãe tomada pela angústia de ter que interromper o choro de seu bebê, a qualquer custo, dada a ameaça de ter que entregá-lo a um familiar ou abrigo institucional se a criança não respeitar o horário de silêncio estabelecido: "Se ela [a bebê] acordar e chorar e, no caso, a senhora [agente penitenciária] subir e ver ela chorando, ela chama a minha atenção e, se acontecer mais vezes, ela faz um comunicado e eu posso até perder minha filha. Eles podem mandar minha filha embora com a minha família [...]" (INSTITUTO TERRA, TRABALHO E CIDADANIA, 2017, p. 156). Fácil constatar a inadequação da presença de um bebê cuja principal forma de interação é o choro - à rotina do estabelecimento prisional.

Retomando o fator de influência do ambiente na formação subjetiva da criança, há que se destacar a absoluta impropriedade do ambiente prisional na função de estimulador para o desenvolvimento de suas potencialidades. Ao contrário, além de limitar o desenvolvimento, há um condicionamento - próprio da prisionalização - a determinadas condutas. Como exemplo, tem-se o caso narrado na obra Mães do Cárcere segundo o qual uma criança nascida no cárcere, com então quase dois anos completos, costumava levantar a blusa numa alusão às repetidas vezes que sua mãe o fazia para passar de um ambiente a outro da unidade prisional (MARTINO, 2017).

Evidencia-se que se os efeitos da prisionalização em adultos já se fazem sentir, ele é ainda mais nefasto na criança. Se é na primeira infância que ela desenvolve sua identidade a partir das interações com o ambiente (físico e social), é preocupante a situação da criança nascida na prisão e que muitas vezes, desde a gestação, já é

\footnotetext{
${ }^{6}$ Dado do ano de 2014.
} 
influenciada por estímulos deletérios: sejam por limitações espaciais sejam por condicionamentos que anulam a individualização da identidade dos sujeitos.

A criança submetida ao ambiente violento e degradante da prisão - nesta etapa da vida - provavelmente terá interrompida ou subdesenvolvida suas capacidades de interação social, inteligência e afetividade. É submetida a um processo de desumanização, de exclusão.

Portanto, diante deste quadro, o que se defende é que seja garantido o exercício da maternidade extramuros, ainda que em prisão domiciliar, com ou sem monitoramento. Se se considera que é mais danosa à criança a separação prematura do que viver os primeiros anos de vida no sistema prisional, que sejam ambos afastados do ambiente carcerário. Encerra-se assim o falso dilema entre nascer preso ou nascer sem mãe.

\section{Considerações finais}

A defesa da melhoria da situação das mulheres e crianças que vivem nas prisões brasileiras passa - preliminarmente - pelo reconhecimento da prisão como espaço de exclusão e violação de direitos, incapaz de assegurá-los no seu interior.

Portanto, os problemas criados pela prisão como o da violação do direito de liberdade dos filhos das mulheres presas, e da restrição ao direito à convivência familiar de ambos não devem ser resolvidos na prisão, mas fora dela.

Tendo em vista que a criança filha da mulher presa não foi condenada à pena privativa de liberdade, é imperativo que haja alteração da Lei de Execução Penal. Nesse sentido, propõem-se a alteração do art. 89 que prevê creche na penitenciária de mulheres para que a previsão legal seja no sentido de garantir o acesso da criança a creches da rede pública, externas ao ambiente prisional e abertas à comunidade.

Cabe mencionar - ainda - como possível referência de alternativa voltada para minimizar os impactos da prisão sobre as mulheres presas com filhos sob a sua responsabilidade, o previsto pela Lei 26.472 da Argentina que autoriza o juiz da execução a decidir sobre o cumprimento da pena imposta em prisão domiciliar para mulher grávida ou mãe.

A Lei 13.257 de 2016, conhecida como Marco da Primeira Infância, estabeleceu diretrizes para a formulação e a implementação de políticas públicas para a primeira infância, considerando a relevância dos primeiros anos de vida no desenvolvimento infantil. Promoveu ainda uma alteração no Código de Processo Penal, 
prevendo a possibilidade de substituição da prisão preventiva pela domiciliar nos casos de gestantes ou mulher com filho de até 12 anos de idade incompletos. Tal previsão poderia ser ampliada para abarcar também as pessoas condenadas que se encontrarem na mesma situação.

Por fim, o indulto e a comutação podem continuar sendo concedidos às mulheres mães, presas, em atenção ao melhor interesse da criança que tem prioridade absoluta; evitando-se, com isso, o seu encarceramento e todos os efeitos deletérios decorrentes dele. 


\section{REFERÊNCIAS}

BARATTA, Alessandro. Criminologia crítica e crítica do Direito Penal: introdução à Sociologia do Direito Penal. 6. ed. Rio de Janeiro: Revan, 2011.

BEIRAS, Iñaki Rivera. Descarcelación. Principios para uma política pública de reducción de la cárcel (desde un garantismo radical). Valencia: Tirant lo blanch, 2017.

BRAGA, Ana Gabriela Mendes; ANGOTTI, Bruna. Da hipermaternidade à hipomaternidade no cárcere feminino brasileiro. SUR - Revista internacional de Direitos Humanos, v. 12, n. 22, p. 229-239, 2015.

BRAGA, Ana Gabriela Mendes. Entre a Soberania da Lei e o Chão da Prisão: a maternidade encarcerada. Revista Direito GV, São Paulo, v. 11, n. 2, p. 523-546, jul/dez. 2015.

BRASIL. Constituição (1988) Constituição da República Federativa do Brasil. Brasília: Senado, 1988.

BRASIL. Lei n ${ }^{\circ} 2.040$, de 28 de setembro de 1871. Declara de condição livre os filhos de mulher escrava que nascerem desde a data desta lei, libertos os escravos da Nação e outros, e providencia sobre a criação e tratamento daquelles filhos menores e sobre a libertação annaul de escravos... Coleção de Leis do Brasil, Rio de Janeiro, 1871. Disponível em: < http://www.planalto.gov.br/ccivil_03/leis/LIM/LIM2040.htm> Acesso em: 19 set. 2017.

BRASIL. Lei 7210 de 11 de julho de 1984. Institui a lei de Execução Penal. Diário Oficial da União, Brasília, 13 de julho de 1984.

BRASIL. Lei 8.069 de 13 de julho de 1990. Dispõe sobre o Estatuto da Criança e do Adolescente e dá outras providências. Diário Oficial da União, Brasília, 13 de julho de 1990.

BRASIL. Lei 11.942 de 28 de maio de 2009. Dá nova redação aos arts. 14, 83 e 89 da Lei $\mathrm{n}^{\mathbf{0}}$ 7.210, de 11 de julho de 1984 - Lei de Execução Penal, para assegurar às mães presas e aos recém-nascidos condições mínimas de assistência. Diário Oficial da União, Brasília, 25 de set. 2009.

BRASIL. Lei 13.257 de 8 de março de 2016. Dispõe sobre as políticas públicas para a primeira infância e altera a Lei ${ }^{\circ}$ 8.069, de 13 de julho de 1990 (Estatuto da Criança e do Adolescente), o Decreto-Lei no 3.689, de 3 de outubro de 1941 (Código de Processo Penal), a Consolidação das Leis do Trabalho (CLT), Diário Oficial da União, Brasília, 9 de mar. de 2016. Disponível em: < http://www.planalto.gov.br/ccivil_03/_ato20152018/2016/lei/l13257.htm> Acesso em: 19 set. 2017.

BRASIL. Ministério da Justiça. Departamento Penitenciário Nacional. Levantamento nacional de informações penitenciárias: INFOPEN mulheres. Brasília: INFOPEN, 2014. 
BRASIL. Ministério da Justiça. Secretaria de Assuntos Legislativos. Dar a luz na sombra: condições atuais e possibilidades futuras para o exercício da maternidade por mulheres em situação de prisão. Brasília: IPEA, 2015.

CARRARA, Francesco. Opuscoli di diritto criminale. Seconda edizione correta, amplaiata e riordinata. Lucca: Tipografia Giusta, 1870. v. 2.

DIDONET, Vital. Educação infantil: entrevista com Vital Didonet. TV Câmara, abr. 2016. Entrevista concedida a André Uesato (direção e roteiro). Disponível em: <http://primeirainfancia.org.br/category/acervo/> Acesso em: 25 jul. 2017.

FERRAJOLI, Luigi. Jurisdicción y ejecución penal. La cárcel: una contradicción institucional. Revista Crítica Penal y Poder, n. 11, p.1-10, sep. 2016.

FOUCAULT, Michel. Vigiar e punir: nascimento da prisão. Tradução de Raquel Ramalhete. 40. ed. Petrópolis: Vozes, 2012.

INSTITUTO TERRA, TRABALHO E CIDADANIA. Mulheres em prisão: desafios e possibilidades para reduzir a prisão provisória de mulheres. [S.1]: ITTC, 2017.

Disponível em: <http://ittc.org.br/wpcontent/uploads/2017/03/relatorio_final_online.pdf> Acesso em: 26 jul. 2017.

MARTINO, Natália. Mães do cárcere. Belo Horizonte: NITRO, 2017.

ORMEÑO, Gabriela Reyes; PEREIRA, Ana Carina Stelko. Filhos nascidos no cárcere e as dificuldades do exercício da maternidade em ambiente prisional. Psicologia Argumento, v. 33, n.82, p. 432-445, jul/set. 2015.

QUEIROZ, Nana. Presos que menstruam. 3. ed. Rio de Janeiro: Record, 2015.

SCHEINVAR, Estela. O feitiço da política pública: escola, sociedade civis e direitos da criança e do adolescente. Rio de Janeiro: Lamparina, FAPERJ, 2009.

ZAFFARONI, Eugênio Raúl et al. Direito penal brasileiro: teoria geral do Direito Penal. 2.ed. Rio de Janeiro: Revan, 2003. v. 1. 